\title{
Drying Nerium Oleander in an Indirect Solar Dryer Using Phase Change Material as an Energy Storage Medium
}

\author{
S. M. Shalaby and M. A. Bek
}

\begin{abstract}
In this work, the Nerium Oleander was dried at its prescribed drying temperature $\left(50 \pm 2.5^{\circ} \mathrm{C}\right)$ in indirect solar dryer (ISD) using phase change material (PCM) as energy storage medium. $12 \mathrm{~kg}$ of paraffin wax were used as a latent heat thermal storage. From the experimental obtained results it is found that the ISD implementing PCM as thermal storage medium successfully maintains the temperature of drying air around $50{ }^{\circ} \mathrm{C}$ for seven consecutive hours. It is also found that the temperature of drying air is higher than ambient temperature by $2.5-5{ }^{\circ} \mathrm{C}$ after sunset for $5 \mathrm{hrs}$ at least. This profile of the temperature of drying air helps reaching the final moisture content of Nerium Oleander after $14 \mathrm{hrs}$. Nine thin layer drying mathematical models were tested to specify the suitable model for describing the drying behavior of the Nerium Oleander. It was found that Midilli and Kucuk model is convenient to describe the thin layer solar drying of Nerium Oleander.
\end{abstract}

Index Terms-Solar drying, nerium oleander, energy storage, PCM.

\section{INTRODUCTION}

Medical plant loses its valuable contents when it is exposed to direct solar radiation or when treated with high oven temperature. So there is deep need for a new design for the indirect solar dryer that is able to dry the medical plants and maintain all its valuable contents at the same time. Moreover, the valuable medical plants will be dried then it will be economically beneficial as a result of storing it and/or exporting it.

Nerium Oleander is used as a decorative tree for both streets and school gardens neglecting its medical content. The chemical analysis of Nerium Oleander indicates a large amount of glycoside as reported in [1], [2]. The glycoside medical component is economically important as it is used in heart treatment [3], [4].

A few types of medical plants are dried using the indirect solar dryer such as mints [5], [6] and thymus [5]. Although most of these studies concern the drying curves and their suitable mathematical modeling description, they ignore the important factor of the best desired plants drying temperature.

The phase change material (PCM) ability to store large amount of thermal energy during its melting process and benefit of it under constant temperature later, makes it excellent tool to improve the solar drying system. Limited

Manuscript received March 27, 2014; revised June 28, 2014. This work was funded by the research projects program, Research fund, Tanta University, Egypt, Grants (TU-04-31-03).

S. M. Shalaby and M. A. Bek are with the Department of Engineering Physics and Mathematics, Faculty of Engineering, Tanta University, Tanta, Egypt (e-mail: saleh_shalaby@yahoo.com, malibec2005!@yahoo.com). researchers [7]-[11] utilized the PCM in solar drying system. Although these studies show that the implementing of the PCM in the solar dryer improves thermal performance of the drying system, it ignores the heat losses. Besides, they do not examine their drying system for drying medical plants.

In this work, for the first time, the Nerium Oleander was dried at its prescribed drying temperature $\left(50 \pm 2.5^{\circ} \mathrm{C}\right)$ in an indirect solar dryer (ISD), in which the PCM storage unit is located at the inner bottom of the drying compartment to reduce the heat losses.

\section{MEASUREMENTS AND EXPERIMENTAL PREPARATION}

The ISD was designed and fabricated in the Solar Energy Laboratory workshop, Faculty of Engineering, Tanta University. Complete design details of the air heater, drying compartment and PCM storage unit can be found elsewhere [12]. The ISD implementing PCM was tested using the test rig shown in Fig. 1. The experiments were conducted outdoors during October 2013. The global solar radiation on a $\left(30^{\circ}\right)$ tilted surface, $I$, was measured using a high precision Pyranometer model MS-802 (sensitivity of 7.03 ( $\mu$ volts/W $\left.\mathrm{m}^{2}\right)$ ). Calibrated K-Type thermocouples $\left(0\right.$ to $\left.1100{ }^{\circ} \mathrm{C}\right)$ coupled with KYORITSU KEW1011 multimeter were used to measure the temperatures at different locations of the heater and drying compartment as seen in Fig. 1. The temperatures of the drying air at each tray were measured and its average value, $T_{d a(a v)}$, was obtained. A three-phase induction motor (Type K 120 T, $0.75 \mathrm{HP}, 2.5 \mathrm{~A}, 390 \mathrm{~V}, 50$ $\mathrm{Hz}, 2610 \mathrm{r} / \mathrm{min})$ coupled with a fan $(0.3 \mathrm{~m}$ diameter $)$ was used to blow the air to the drying compartment. The air flow rate was controlled and measured with the help of SJ 300 Hitachi inverter and pitot tube, respectively.

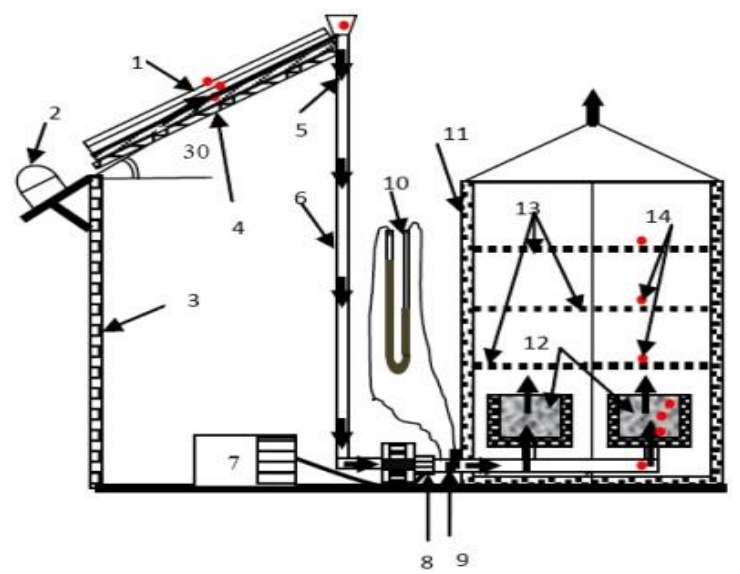

1-Solar air heater; 2-Pyranometer; 3-The room wall; 4-The room roof; 5Flowing air; 6-PVC tube; 7-Inverter; 8-Three phase induction motor coupled with fan; 9-Pitot tube; 10-U tube manometer; 11-Drying compartment; 12PCM; 13-Trays; 14-Thermocouple positions.

Fig. 1. A schematic diagram of the experimental setup. 
The Nerium Oleander was collected from the faculty of pharmacy's research farm in order to be dried by the ISD. There are several considerations which took place during the drying process. Initially the spoiled plants were discarded to avoid products contamination from bacteria. Moreover, selected plants of same size were chosen carefully to ensure the physical characteristics uniformity. Then the selected plants were cleaned using tab water to remove any undesired materials. Cotton clothes were used to remove any water remains from the surface of the plants.

In order to determine the initial moisture content, the plants were weighed while they were fresh then dried at electric oven for 48 hours on $70^{\circ} \mathrm{C}$ and the dried products were weighed for the second time. A digital balance, type $300-9213 / \mathrm{b} 125 \mathrm{~A}$, of readability $0.0001 \mathrm{gm}$ was used to measure the mass of the sample every 60 minutes until it reaches a constant weight.

\section{A. Drying Parameters}

In this section, the governing equations of the drying process and its basic definitions are introduced. The initial moisture content on dry base $M_{0 d}$ is defined as the mass of moisture present in the sample per unit mass of dry matter in the sample [13]:

$$
M_{0 d}=\left(m_{0}-m_{d}\right) / m_{d}
$$

Similarly, $M_{o w}$ is calculated as follow:

$$
M_{0 w}=\left(m_{0}-m_{d}\right) / m_{0}
$$

The moisture content $M_{t d}$ at any given time on dry base is computed using the following expression as presented in [14]:

$$
M_{t d}=\left[\frac{\left(M_{o d}+1\right) m_{t}}{m_{0}}-1\right]
$$

$M_{t w}$ can be calculated from the following equation [15]:

$$
M_{t w}=1-\left(\frac{1}{M_{t d}+1}\right)
$$

The moisture ratio $M R$ is defined as:

$$
M R=\frac{\left(M_{t}-M_{e}\right)}{\left(M_{0}-M_{e}\right)}
$$

The moisture ratio $M R$ is simplified by some investigators [6], [16] to $M_{t} / M_{0}$ because the equilibrium moisture $M_{e}$ content is significantly less than the initial moisture content $M_{0}$. In this case, (5) becomes

$$
M R=\frac{M_{t}}{M_{0}}
$$

The mass shrinkage ratio $(S R)$ is defined as [17]:

$$
S R=m_{t} / m_{0}
$$

The drying thermal efficiency is given as [18]:

$$
\eta_{d}=\frac{m L}{I_{a v} A t}
$$

TABLE I: MATHEMATICAL Models APPLIED to THE SOLAR DRYING

\begin{tabular}{ccr}
\hline $\begin{array}{c}\text { Model } \\
\text { name }\end{array}$ & Model equation & Reference \\
\hline Lewis & $M R=\exp (-k t)$ & {$[19]$} \\
Page & $M R=\exp \left(-k t^{n}\right)$ & {$[20]$} \\
$\begin{array}{c}\text { Modified } \\
\text { Page }\end{array}$ & $M R=\exp \left(-(k t)^{n}\right)$ & {$[21]$} \\
$\begin{array}{c}\text { Henderson } \\
\text { and Pabis }\end{array}$ & $M R=a \exp (-k t)$ & {$[22]$} \\
$\begin{array}{c}\text { Logarithmi } \\
\text { c }\end{array}$ & $M R=a \exp (-k t)+c$ & {$[23]$} \\
$\begin{array}{c}\text { Two term } \\
\text { Modified }\end{array}$ & $M R=a \exp \left(-k_{0} t\right)+b \exp \left(-k_{1} t\right)$ & {$[24]$} \\
$\begin{array}{c}\text { Henderson } \\
\text { and Pabis } \\
\text { Verma } e t \\
a l .\end{array}$ & $M R=a \exp (-k t)+(1-a) \exp (-g t)$ & {$[26]$} \\
$\begin{array}{c}\text { Midilli and } \\
\text { Kucuk }\end{array}$ & $M R=a \exp \left(-k t^{n}\right)+b t$ & {$[27]$} \\
\hline
\end{tabular}

Moreover, the thin layer drying equations given in Table I [19]-[27] are tested to select the most suitable model for describing the drying curve of Nerium Oleander. For model evaluation, a nonlinear regression analysis is used. The correlation coefficient $R$, the statistical parameter reduced chi-square $x^{2}$, and root mean square errors RMSE are used to determine the quality of the fit. The higher value of $R$ and the lower values of $x^{2}$ and RMSE are chosen as the criteria for goodness of fit. The reduced chi-square $x^{2}$ and the root mean square errors RMSE are calculated as follows [28]:

$$
\begin{gathered}
x^{2}=\frac{\sum_{i=1}^{N}\left(M R_{\exp , i}-M R_{p r e, i}\right)^{2}}{N-n} \\
R M S E=\sqrt{\frac{\sum_{i=1}^{N}\left(M R_{\text {exp } \dot{i}}-M R_{p r e, i}\right)^{2}}{N}}
\end{gathered}
$$

where $M R_{\text {exp. } i}$ stands for the experimental moisture ratio found in the measurements; $M R_{\text {pre. }}$ is the predicted moisture ratio for this measurement; $N$ is the number of observations; and $n$ is the number of a model's constants.

\section{RESULTS AND DISCUSSIONS}

The ISD implementing PCM is used to dry Nerium Oleander on a typical day of October 2013 where the maximum measured values of solar radiation and ambient temperature are $1109 \mathrm{~W} / \mathrm{m}^{2}$ and $31^{\circ} \mathrm{C}$, respectively as seen in Fig. 2. The variation of the average value of drying air temperature $T_{d a(a v)}$ is also shown in Fig. 2. The ISD implementing PCM as thermal storage medium successfully maintains $T_{d a(a v)}$ around $50^{\circ} \mathrm{C}$ for seven consecutive hours as clearly seen in Fig. 2. It is also seen in Fig. 2 that $T_{d a(a v)}$ is 
higher than ambient temperature by $2.5-5^{\circ} \mathrm{C}$ after sunset for 5 $\mathrm{hrs}$ at least. This profile of drying temperature helps reaching the final moisture content of Nerium Oleander after $14 \mathrm{hrs}$ as clearly seen in Fig. 3. The shrinkage ratio is 0.367 as calculated from (6). Variation of moisture ratio of one $\mathrm{kg}$ of Nerium Oleander with drying time is shown in Fig. 4. The thin layer drying models given in Table I are applied on the drying curve of Nerium Oleander represented in Fig. 4 and the obtained statistical results are summarized in Table II. From the results of Table II it is seen that Midilli and Kucuk model gives the highest correlation coefficient $(R=0.9981$ ) and the lowest reduced chi-square $\left(x^{2}=0.000336\right)$ and lowest root mean square error $(R M S E=0.01625)$; therefore, it is selected to describe the thin layer drying behavior of Nerium Oleander. The thin layer drying model of Nerium Oleander is obtained as:

$$
M R=1.0073 \exp \left(-0.1365 t^{1.1306}\right)+0.01 t
$$

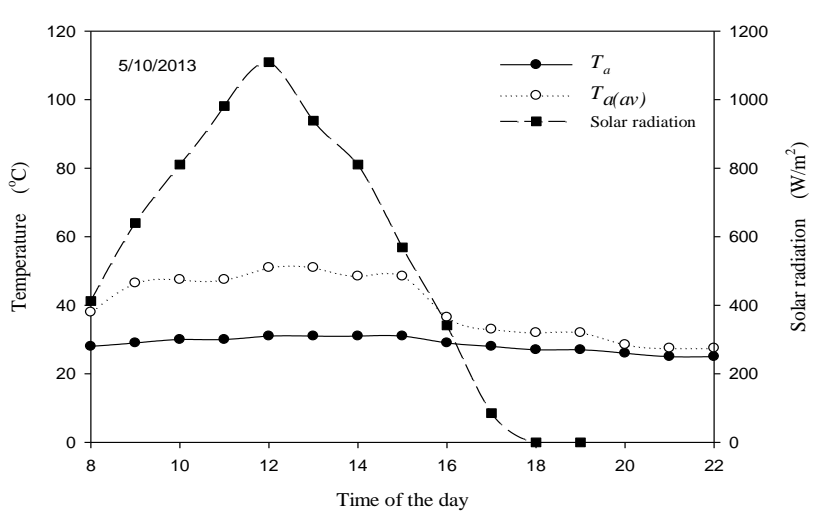

Fig. 2. The variation of drying temperature VS time.

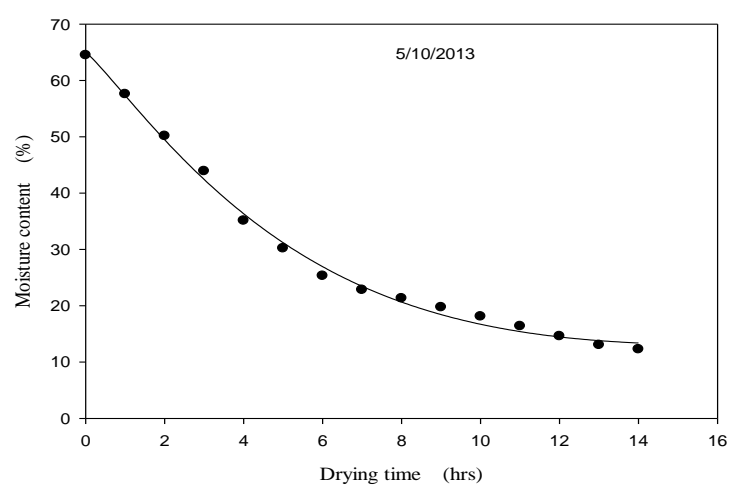

Fig. 3. The variation of moisture content of one $\mathrm{kg}$ of Nerium Oleander with the drying time.

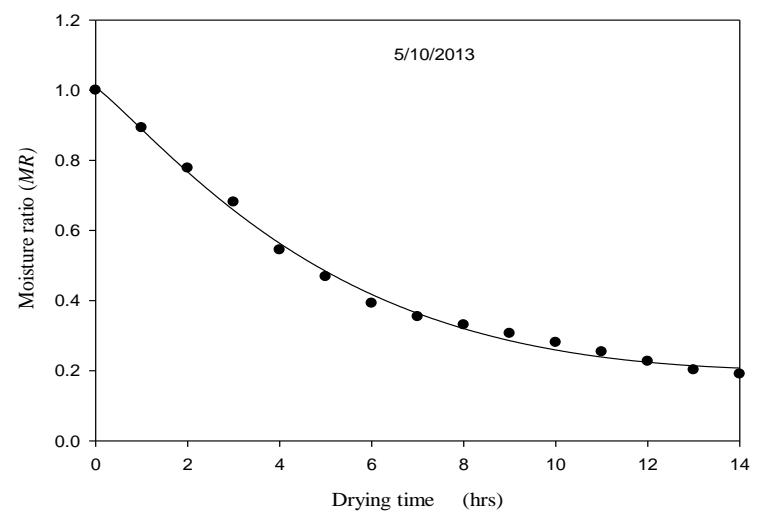

Fig. 4. The variation of moisture ratio of one $\mathrm{kg}$ of Nerium Oleander with the drying time.
TABLE II: STATISTICAL RESUlTS OF MATHEMATICAL MODELING OF

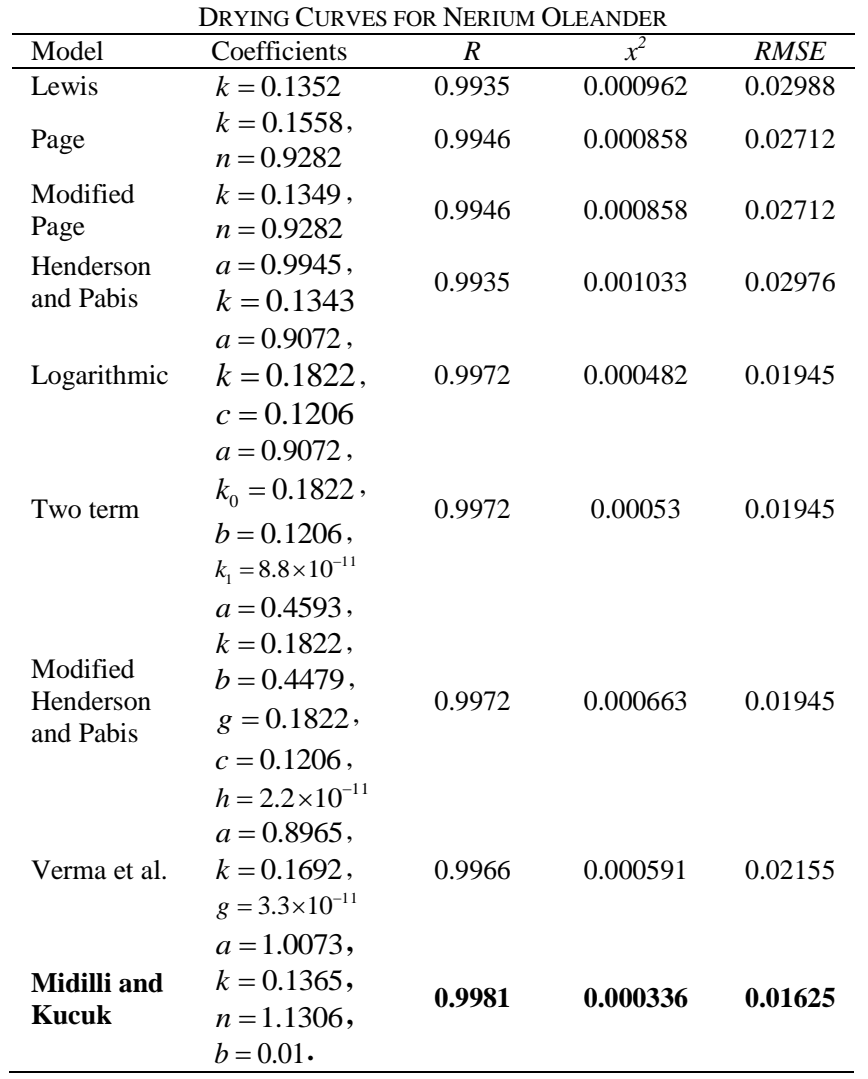

Comparison between experimental moisture ratio and that predicted using Midilli and Kucuk model for Nerium Oleander is shown in Fig. 5. From this figure it is clear that, the established model (11) provided good conformity between experimental and predicted moisture ratios, and the predicted data generally banded around a $45^{\circ}$ straight line. This means that, this model is valid in describing the thin layer solar drying behavior of Nerium Oleander for given operating drying parameters.

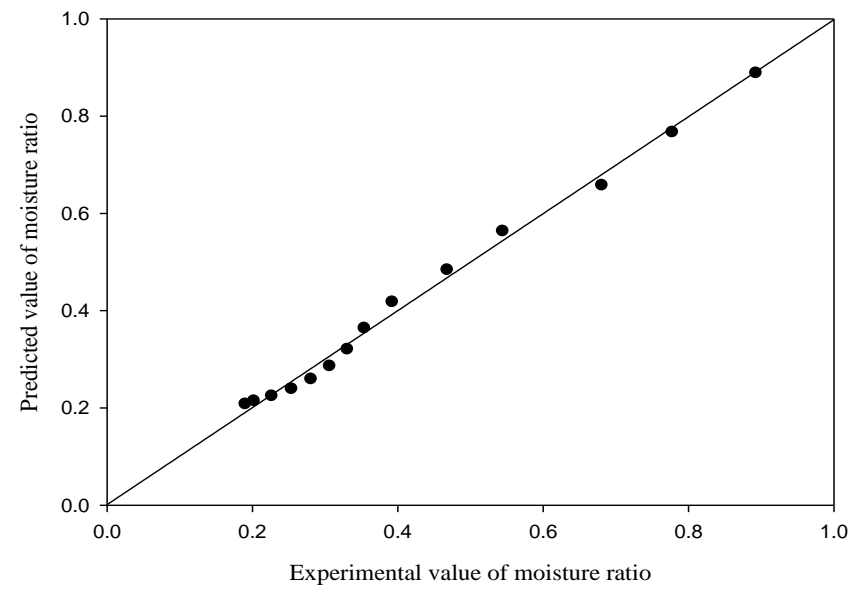

Fig. 5. Comparison between experimental moisture ratios (MR) and that predicted for Nerium Oleander calculated using Midilli and Kucuk model.

\section{CONCLUSIONS AND RECOMMENDATIONS FOR FUTURE WORK}

The ISD implementing PCM is experimentally tested for drying Nerium Oleander. From the experimental obtained results it is concluded that the utilization of PCM in the ISD smoothes the temperature of dying air and provide a suitable 
temperature for drying Nerium Oleander during $14 \mathrm{hrs}$. It is inferred that using high thermal conductive particles with paraffin wax as energy storage material may improve the thermal performance of the indirect solar dryer.

\section{NOMENCLATURE}

I the global solar radiation on a $\left(30^{\circ}\right)$ tilted surface $\left(\mathrm{W} / \mathrm{m}^{2}\right)$

ISD indirect solar dryer

$L \quad$ latent heat of water $(\mathrm{kJ} / \mathrm{kg})$

$M_{o d}$ initial moisture content on dry base

$M_{o w}$ initial moisture content on wet base

$M_{f} \quad$ final moisture content

$M_{t d}$ instantaneous moisture content on dry base

$M_{t w}$ instantaneous moisture content on wet base

$\dot{m}$ mass flow rate of air $(\mathrm{kg} / \mathrm{s})$

$m_{o} \quad$ initial mass of the sample $(\mathrm{kg})$

$m_{d} \quad$ mass of the dried sample $(\mathrm{kg})$

$m_{t} \quad$ mass of the sample at any time $(\mathrm{kg})$

$m_{e} \quad$ mass of water evaporated $(\mathrm{kg})$

PCM phase change material

$S R \quad$ shrinkage ratio (dimensionless)

$T_{a} \quad$ ambient temperature $\left({ }^{\circ} \mathrm{C}\right)$

$T_{d a(a v)}$ average temperature of drying air $\left({ }^{\circ} \mathrm{C}\right)$

$T_{d a(i)}$ temperature of drying air at the entrance of the drying compartment $\left({ }^{\circ} \mathrm{C}\right)$

$t$ drying time (s)

$\begin{array}{ll}\text { Subscripts: } \\ a v & \text { average } \\ d & \text { drying } \\ i & \text { inlet } \\ o & \text { outlet } \\ t h & \text { thermal }\end{array}$

\section{Greek:}

$\eta \quad$ efficiency (dimensionless)

\section{REFERENCES}

[1] S. Singh, S. Shenoy et al, "Nerium oleander derived cardiac glycoside oleander in is a novel inhibitor of HIV infectivity," Fitoterapia, vol. 84, pp. 32-39, 2013.

[2] B. S. Siddiqui, N. Khatoon, S. Begum, A. D. Farooq, K. Qamar, H. A. Bhatti, and S. K. Ali, "Flavonoid and cardenolide glycosides and a pentacyclictriterpene from the leaves of Nerium oleander and evaluation of cytotoxicity," Phytochemistry, vol. 77, pp. 238-244, 2012.

[3] Y. Sreenivasan, P. B. Raghavendra, and S. K. Manna, "Oleandrin-mediated expression of Fas potentiates apoptosis in tumor cells," J ClinImmunol, vol. 26, pp. 308-322, 2006.

[4] P. Yang, D. G. Menter, C. Cartwright, D. Chan, S. Dixon, and M. Suraokar, "Oleandrin-mediated inhibition of human tumor cell proliferation: Importance of $\mathrm{Na}, \mathrm{K}-\mathrm{ATPase}$ alpha subunits as drug targets," Mol Cancer Ther., vol. 8, pp. 2319-2328, 2009.

[5] A. A. El-Sebaii and S. M. Shalaby, "Experimental investigation of an indirect-mode forced convection solar dryer for drying thymus and mint," Energy Conversion and Management, vol. 74, pp. 109-116, 2013.

[6] E. K. Akpinar, "Drying of mint leaves in a solar dryer and under open sun: modeling, performance analyses," Energy Conversion and Management, vol. 51, pp. 2407-2418, 2010.

[7] S. Devahastin, K. W. Ng, and A. S. Mujumdar, "Preliminary study of a novel thermal storage-spouted bed contactor for particulate drying," in Proc. $48^{\text {th }}$ Canadian Chemical Engineering Conference, 1989.

[8] S. Devahastin and S. Pitaksuriyarat, "Use of latent heat storage to conserve energy during drying and its effect on drying kinetics of a food product," Applied Thermal Engineering, vol. 26, pp. 1705-1713, 2006.

[9] L. M. Bal, P. Sudhakar, S. Satya, and S. N. Naik, "Review of Solar dryer with latent heat storage systems for drying agricultural food products," Renewable and Sustainable Energy Reviews, vol.15, issue 1, pp. 876-880, 2009.

[10] G. Cakmak, C. Yidiz, "The drying kinetics of seeded grape in solar dryer with PCM-based solar integrated collector," Food and Bioproducts Processing, vol. 89, pp. 103-108, 2011.

[11] S. Esakkimuthu, A. Hassabou, C. Palaniappan, M. Spinnler, J. Blumenberg, and R. Velraj, "Experimental investigation on phase change material based thermal storage system for solar air heating applications," Solar Energy, vol. 88, pp. 144-153, 2013.

[12] S. M. Shalaby and M. A. Bek, "Experimental investigation of a novel indirect solar dryer implementing PCM as energy storage medium," Energy Conversion and Management, vol. 83, pp. 1-8, 2014.

[13] I. Doymaz, "Thin layer drying behaviour of mint leaves," Journal of Food Engineering, vol. 74, pp. 370-375, 2006.

[14] A. A. El-Sebaii, S. Aboul-Enein, M. R. I. Ramadan, and H. G. El-Gohary, "Experimental investigation of an indirect type natural convection solar dryer," Energy Conversion and Management, vol. 43 , pp. 2251-2266, 2002.

[15] M. A. Zaman and B. K. Bala, "Thin layer solar drying of rough rice," Solar Energy, vol. 42, pp. 167-171, 1989.

[16] A. Midilli and H. Kucuk, "Mathematical modeling of thin layer drying of pistachio by using solar energy," Energy Conversion and Management, vol. 44, pp. 1111-1122, 2003.

[17] A. Midilli, "Determination of pistachio drying behavior and conditions in a solar drying system," Int. J. Drying Res., vol. 25, pp. 715-725, 2001.

[18] P. P. Singh, S. Singh, and S. S. Dhaliwal, "Multi-shelf domestic solar dryer," Energy Conversion and Management, vol. 47, pp. 1799-1815, 2006.

[19] W. K. Lewis, "The drying of solid materials," Journal Indian Engineering, vol. 5, pp. 427-433, 1921.

[20] G. E. Page, "Factors influencing the maximum rates of air drying shelled corn in thin layers," Master Thesis, Purdue University, Lafayette, IN, USA, 1949.

[21] G. M. White, I. J. Ross, and R. Ponelert, "Fully exposed drying of popcorn," Transactions of the American Society of Agricultural Engineers, vol. 24, pp. 466-468, 1981.

[22] M. S. Chinnan, "Evaluation of selected mathematical models for describing thin layer drying of in-shell pecains," Transactions of the American Society of Agricultural Engineers, vol. 27, pp. 610-615, 1984.

[23] A. Yagcioglu, A. Degirmencioglu, and F. Cagatay, "Drying characteristics of laurel leaves under different conditions," in Proc. the Seventh International Congress on Agricultural Mechanization and Energy, Adana, Turkey. Faculty of Agriculture, Cukurova University, 1999, pp. 565-569.

[24] S. M. Henderson, "Progress in developing the thin layer drying equation," Transactions of the American Society of Agricultural Engineers, vol. 17, pp. 1167-1168, 1974.

[25] V. T. Karathanos, "Determination of water content of dried fruits by drying kinetics," Journal of Food Engineering, vol. 39, pp. 337-344, 1999.

[26] L. R. Verma, R. A. Bucklin, J. B. Endan, and F. T. Wratten, "Effects of drying air parameters on rice drying models," Transactions of the American Society of Agricultural Engineers, vol. 28, pp. 296-301, 1985.

[27] A. Midilli, H. Kucuk, and Z. Yapar, "A new model for single layer drying," Drying Technology, vol. 20, pp. 1503-1513, 2002.

[28] C. Ertekin and O. Yaldiz, "Drying of eggplant and selection of a suitable thin layer drying model," Journal of Food Engineering, vol. 63, pp. 349-359, 2004.

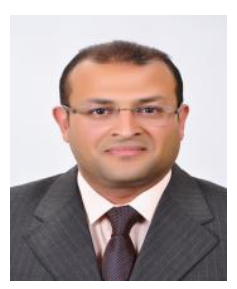

S. M. Shalaby was born in Tanta, Egypt, in February 1974. He completed Ph.D. degree in engineering physics and mathematics (engineering physics) on 2012 from Tanta University, Tanta, Egypt. The thesis entitled "Investigation of thermal performance of indirect solar drying systems". He received his M. SC. degree in engineering physics and mathematics (engineering physics) on 2005 from Tanta University, Tanta, Egypt. The thesis entitled "Utilization of solar energy in some flat plate solar collectors". He finished his B. SC. degree in machines and electrical power engineering with grade "very good with honor" on 1997 from Tanta University, Tanta, Egypt.

Currently he is a lecturer at Engineering Physics and Mathematics Dep., Faculty of Engineering, Tanta Univ., from February 28, 2012.

He has a strong experience in the field of solar energy and its applications. The focus of some of his current studies is the utilization of phase change 
material as energy storage medium in solar thermal energy applications. He is currently the principal investigator of the research project: "Novel indirect solar dryer design to dry medical plants using PCM as storage medium". $\mathrm{He}$ has published several research papers in international Journals.

Dr. Shalaby is a senior member of Asia-Pacific Chemical, Biological\& Environmental Engineering Society (APCBEES). Dr. Shalaby is also a member of Science and Engineering institute (SCIEI).

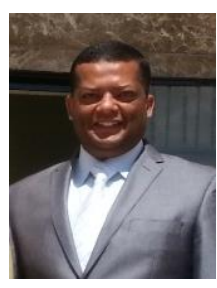

M. A. Bek was born in Cairo, Egypt, in April 1972. He completed $\mathrm{PhD}$ Degree in environmental engineering, School of Chemical and Environmental Engineering, University of Nottingham, UK. Thesis title is "Numerical simulation of the water haydrodynamics of Lake El-Manzala, Egypt." He received his MSc degree in applied mathematics, form Physics and Engineering Mathematics Department, Tanta 1 University, Egypt, February 2004. Thesis title is "Perturbed Motion of a dynamical System". He finished his B.Sc. degree in mechanical engineering, Faculty of Engineering, Tanta University, EGYPT, June 1996. Currently he is a lecturer at Engineering Physics and Mathematics Dep., Faculty of Engineering, Tanta Univ., in addition he is a visiting lecturer at Misr University for Technology and science. He has published several research papers in international Journals.

$\mathrm{He}$ obtained his $\mathrm{PhD}$ in environmental engineering from the University of
Nottingham, UK in 2011. His PhD research focused on developing a field validated numerical model to investigate the water hydrodynamic of lake El-Manzala, Egypt. He is interested in the development and application of computational models to provide an improved understanding of the fundamental processes that cause real world environmental engineering problems, and which may assist in the design of sustainable solutions to these problems. The focus of some of his current and recent research studies is the modeling of the water hydrodynamics and water quality of lakes. In addition, solar energy applications are became of his most recent interest. A Novel indirect solar dryer to dry medical plants using PCM as storage medium was designed and investigated. This project was funded through Tanta University, Egypt. 